University of Nebraska - Lincoln

DigitalCommons@University of Nebraska - Lincoln

Faculty Publications: Agricultural Economics

Agricultural Economics Department

8-1-1993

\title{
Measures of Waste Due to Quotas
}

Lilyan E. Fulginiti

University of Nebraska-Lincoln, Ifulginiti1@unl.edu

Richard K. Perrin

University of Nebraska-Lincoln, rperrin@unl.edu

Follow this and additional works at: https://digitalcommons.unl.edu/ageconfacpub

Part of the Agricultural and Resource Economics Commons

Fulginiti, Lilyan E. and Perrin, Richard K., "Measures of Waste Due to Quotas" (1993). Faculty Publications: Agricultural Economics. 14.

https://digitalcommons.unl.edu/ageconfacpub/14

This Article is brought to you for free and open access by the Agricultural Economics Department at DigitalCommons@University of Nebraska - Lincoln. It has been accepted for inclusion in Faculty Publications: Agricultural Economics by an authorized administrator of DigitalCommons@University of Nebraska - Lincoln. 


\section{Measures of Waste Due to Quotas}

\section{Lilyan Fulginiti and Richard Perrin}

This paper addresses the issue of measuring welfare losses due to imposition of a production quota. The topic of welfare measurement is important in agriculture because production quotas are a ubiquitous component of agricultural policy. While it is probably true that in the arena of policy decisions, the somewhat subtle distinctions of alternative measures of loss will usually be swamped by errors in measuring them; nonetheless it is important that economists, at least, be clear about which concepts are being measured and why. Our objective is to briefly elaborate two alternative general equilibrium concepts (Diewert) of the welfare loss due to the imposition of a production quota, and to illustrate their use by considering costs of the U.S. tobacco program. In addition to the two concepts elaborated here, other alternatives might be considered, and there is good reason to evaluate them for an open economy, rather than the closed economy model used here. Space considerations dictate that these alternatives be considered in another paper.

\section{Measures of Deadweight Loss}

Since early in the last century, economists have wrestled with the problem of conceptualizing and measuring the cost to the economy of various inefficiencies. The sources of inefficiencies vary, but Debreu's classification distinguishes underemployment (for example, unemployed workers, idle machinery or land), technical inefficiency in production, and imperfection of economic organization (producing or consuming units face prices that differ because of taxes, quotas, subsidies or other institutional restrictions.) Under any of these circumstances, a feasible reallocation of resources can make some

The authors are, respectively, assistant professor of Economics, Iowa State University, and professor of Agricultural and Resource Economucs, North Carolina State University

Joumal paper No J-15260 of the Iowa Agriculture Home Economics Experiment Station, Ames, Iowa Project No 2998 Partial support was provided by the North Carolına Agricultural Experiment Station households better off without making others worse off. At issue is an appropriate measure of this foregone opportunity, known variously as "waste," "deadweight loss," "excess burden," "surplus," and other less familiar terms. In this study we use the term deadweight loss, or simply "loss."

Dupuit, Marshall, Hicks, and others developed and extended the notion of consumers' surplus (and the related idea of producers' surplus), which is a useful building block in evaluating loss. However, such partial equilibrium concepts are conceptually inadequate because they do not address the gains or losses imposed on the remainder of the economy when reallocations are made to particular consumers or in the markets for particular commodities. Thus the conceptual framework must be based on some type of general equilibrium analysis. This approach to measuring loss has it roots in the work of Pareto, with more recent contributions by Allais and Debreu, whose work Diewert refers to as "quantity-oriented" (measuring loss in units of goods), and by Boiteux, who extended Hicks" "price oriented" variations (which measure loss in terms of currency) to a general equilibrium framework. While these general equilibrium approaches (including those of Diewert, and Kay and Keen who reconciled and extended the earlier efforts) focused on taxation as the cause of loss, they can be modified to consider the case of a public good as a cause (as in Tsuneki), or the case of production quotas as is considered in this paper.

Allais and Debreu measure loss (A-D loss hereafter) as the amount of a particular good (Allais) or a particular bundle of goods (the initial resource bundle, for Debreu) that could be extracted from the economy and discarded, without making any household worse off. For a given state of the economy, the maximum amount of such a surplus is an intuitive measure of the loss inherent in that state compared to an efficient reallocation. The Allais-Debreu approach involves comparison of an existing equilibrium (presumably distorted) with a hypothetical reference equilibrium in which all households are at the same utility level as at the distorted equi- 
librium, but some physical good or goods have been extracted. The reference equilibrium is hypothetical in that the analysis does not presuppose that such a reallocation would actually occur, even though an omniscient government might affect such a reallocation and redistribute the distributable surplus in some way that is irrelevant to the measure itself.

It is useful here to refer to the geometric interpretation in figure 1 for the case of a two-good economy, a numéraire good $x$ and a good $q$ for which a production quota constrains output to $q_{0}$. The right-hand panel shows the production possibilities curve and a constant-utility-allocation curve $(U)$ indicating the minımum combinations of goods that can be distributed to keep all consumers at the levels of utility they enjoy at the initial distorted equilibrium indicated by point A. An Allais measure of loss is the quantity of good $x$ indicated by the length of line segment $\mathrm{AC}$-AP, where $\mathrm{AC}$ indicates consumption at the Alla1s-Debreu reference equilibrium and AP indicates production at the reference equilibrium. It can also be shown that this quantity of $x$ is equal to the triangle abc in the lefthand panel, where $D^{h}$ is a Hickssan-like utilityallocation-constant compensated aggregate demand curve for good $q$, and $S$ is the marginal rate of transformation ("supply") curve. This social surplus triangle differs from comparable Marshallian surplus triangles in that the supply curve is a general equilibrium supply curve (no other prices are held constant; in the two good case there are no other prices), and in that the compensated demand curve holds all households at their initial utility levels.

We restrict our attention in this study to the losses from quotas that are optimally distributed among firms, as would be presumed to occur in the case of freely tradeable quotas. If quotas are arbitrarily distributed among firms (as is the case for tobacco), the distorted equilibrium (point $\mathrm{A}$ in figure 1) will lie inside the production possibilities frontier, and losses would be incurred beyond those conceptualized in this paper (see Alston and Sumner for further consideration of this point.)

While Hicks developed the concept of compensating variation (as well as other relevant measures) to measure the value to a particular corsumer of moving from one bundle of goods 10 another, it was Boiteux who extended this notion to a general equilibrium concept of loss. The Hicks-Boiteux measure of loss (H-B loss, hereafter) is the amount of income equivalent to the gains consumers would realize by reallocating from an existing equilibrium in an optimal way so as to maximize a welfare function that
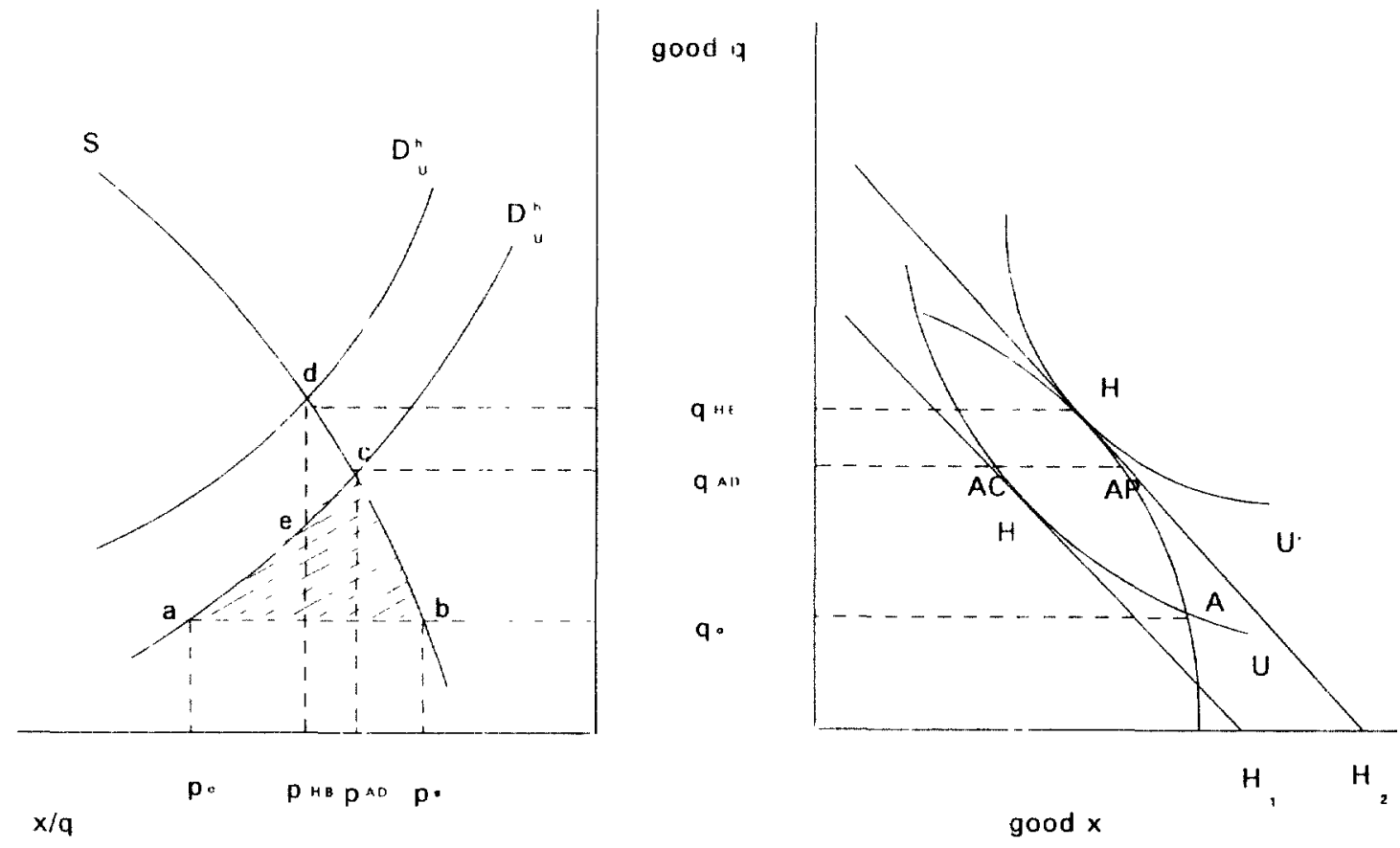

Figure 1. A-D and H-B measures of loss due to a quota 
consists of a weighted sum of households' utility functions. The similarity of the H-B loss to the notion of compensating variation is evident from figure 1 . Here the initial equilibrium is again point $\mathrm{A}$, but the reference equilibrium is point $\mathrm{H}$ where the production possibilities curve is tangent to the curve $\mathrm{U}^{\prime}$. In direct analogy to the concept of compensating variation, the $\mathrm{H}-\mathrm{B}$ loss is the length of line segment $\mathrm{H}^{\prime}-\mathrm{H}$, the amount of the numéraire good equivalent (at reference equilibrium price $p^{H B}$ ) to the welfare gain in moving from point $\mathrm{H}^{\prime}$ to point $\mathrm{H}$. It may be shown that this amount is equal to the sum of the areas of triangles $a b c$ and cde in the lefthand panel of figure 1 .

We introduced and geometrically interpreted A-D and $\mathrm{H}-\mathrm{B}$ losses from the imposition of a quota, and from this we observed the similarity of the A-D loss to the familiar notion of welfare triangles and we observed the similarity of $\mathrm{H}-\mathrm{B}$ loss to the familiar notion of compensating variation. The $\mathrm{H}-\mathrm{B}$ loss concept utilizes a reference equilibrium which could (not necessarily would) actually be realized if the quota constraint were relaxed, whereas the $A-D$ reference equilibrium is more hypothetical. However, evaluation of the $\mathrm{H}-\mathrm{B}$ loss requires knowledge of both the "isohedonous" utility-allocation-constant curve and the weights for households (if more than one) necessary to redistribute goods in the optimum welfare-increasing way. The A-D measure has the advantage of requiring "only" the former. We proceed now to sketch out the general equilibrium model that permits us to evaluate these measures of loss, both in general and in the case of a one-person, two-good economy as depicted in figure 1.

\section{Derivation of General Equilibrium Measures of Deadweight Loss}

The description of the economy used here is similar to that of Kay and Keen, but also borrows heavily from Diewert (1981). There are $\mathrm{H}$ households in the economy, each characterized by an expenditure function $e_{h}\left(\mathbf{p}^{\mathbf{c}}, u_{h}\right)=x_{h}+$ $\mathbf{p}^{\mathbf{c}} \mathbf{q}_{\mathbf{h}}$ where $x_{h}$ is consumption of the numéraire good, $\mathbf{q}_{\mathbf{h}}$ is a vector of other goods, $\mathbf{p}^{\mathbf{c}}$ is a vector of consumer prices and $u_{h}$ is utility level. Define the aggregate expenditure function as $E\left(\mathbf{p}^{\mathbf{c}}, u\right)=\Sigma e_{h}\left(\mathbf{p}^{\mathbf{c}}, u_{h}\right)$, where $u$ is an index of the utility allocation $u_{h}$. This aggregate expenditure function defines the minimum total expenditure required to keep each household at $u_{h}$, given consumer prices $\mathbf{p}^{\mathbf{c}}$. Then $E\left(\mathbf{p}^{\mathbf{c}}, u\right)=x+$ $\mathbf{p}^{\mathbf{c}} \mathbf{q}\left(\mathbf{p}^{\mathbf{c}}, u\right)$, where $x$ is the aggregate level of the numéraire good, and $\mathbf{q}\left(\mathbf{p}^{\mathbf{c}}, u\right)$ is aggregate demand for other goods

There are $F$ price-taking firms in the economy, with the profit function of each characterized as $\pi_{f}\left(\mathbf{p}^{\mathbf{s}}\right)=y_{f}+\mathbf{p}^{\mathbf{\prime}} \mathbf{q}+\mathbf{p q}_{\mathbf{f}}$, where $y_{f}$ is the netput of numéraire good (positive if numéraire good is produced, negative if used), $\mathbf{q}_{\mathbf{f}}$ is the vector of other netputs, $\mathbf{p}^{\text {" is the virtual }}$ price vector and $\boldsymbol{\rho} \equiv \mathbf{p}^{\mathbf{c}}-\mathbf{p}^{\mathbf{y}}$ is the price wedge between consumer and virtual prices. The virtual price in the output case is that market price which would call forth production level $\mathbf{q}_{\mathbf{f}}$, in the input case it is that market price which would call forth input use of $\mathbf{q}_{\mathbf{r}}$. In our case, the price wedge is caused by binding quotas imposed on the use or production of some of the commodities (virtual prices are equal to market prices for those commodities with no quota intervention.) Total firm profits in the economy are $\pi\left(\mathbf{p}^{\prime}\right)=y$ $+\mathbf{p}^{\mathbf{s}} \mathbf{q}+\boldsymbol{\rho q}$, consisting of numéraire netput plus "normal" profits at the virtual price p" plus rents $\rho q$.

Individual consumers' expenditures in the economy are constrained by the amount of the initial endowment of numéraire good plus profits from firms. Since this economy is closed and has no government sector, aggregate consumer expenditure is constrained to equal aggregate endowment plus aggregate profits. (The utılity distribution $u_{h}$ will reflect the effects of the distribution of endowments on the expenditure function.) Thus the first general equilibrium equation can be expressed as

$$
\text { (1) } x^{\prime}+\mathbf{p}^{\mathbf{c}} \mathbf{E} .=x_{0}+\pi=x_{0}+y+\left(\mathbf{p}^{\prime}+\mathbf{p}\right) \boldsymbol{\pi}
$$

where $\mathbf{E}$. represents the derivative of $E$ with respect to its vector of price arguments. and so on.

To characterize the possibility of extracting surplus goods from the economy, the vector specifying the content of the basket of goods (numeratre and others) to be extracted is defined as $\left(\alpha_{r}, \boldsymbol{\alpha}\right)$. The number of baskets is $r$, so the vector representing the total quantities of goods extracted is $\left(\alpha_{k}, \boldsymbol{\alpha}\right) r$. Given this, the equations insuring a quantity equilibrium for each commodity are

$$
\begin{aligned}
& x+\alpha_{1} r=x_{0}+y, \text { and } \\
& \mathbf{E} .+\boldsymbol{\alpha r}=\boldsymbol{\pi} .
\end{aligned}
$$

The final equilibrium equation specifies the price wedges previously defined:

$$
\mathbf{p}^{\mathbf{c}}=\mathbf{p}^{\mathbf{s}}+\boldsymbol{\rho}
$$

Differentiation of these equations (invoking the homogeneity conditions $\mathbf{p}^{\mathbf{c}} \mathbf{E} .=\mathbf{p}^{\mathbf{u}} \boldsymbol{\pi} .=0$ where 
appropriate) yields the following set of differential equations describing adjustments in the general equilibrium:

$$
\begin{aligned}
& \mathbf{E} . d \mathbf{p}^{c}+\mathbf{p}^{c} E_{u} d u=d y+\pi \cdot d \mathbf{p}^{\prime} \\
& d x+\alpha_{1} d r=d y \\
& \mathbf{E} . d \mathbf{p}^{c}+\boldsymbol{\alpha} d r=\boldsymbol{\pi} . . d \mathbf{p}^{\prime} \\
& d \mathbf{p}^{\prime}=d \mathbf{p}^{\prime}+d \mathbf{p} \\
& +\boldsymbol{\rho} \boldsymbol{\pi} . . d \mathbf{p}^{s}+\boldsymbol{\pi} \cdot d \rho
\end{aligned}
$$

The two measures of deadweight loss can be ap proximated from equations (4) as described next.

\section{The Allais-Debreu Measure of Loss:}

Although the Hicks-Botteux compensating var1ation is a more familiar deadweight loss measure, we first examine the Allas-Debreu loss because it is simpler. Recall that this measure of loss is the maximum amount of a good. or a basket of goods, that can be extracted from the economy by a reallocation that keeps all consumers at their intial utility levels. Thus for this case, $d t=0$, i e. there is to be no change in the utility allocation. The system of differential equations (4) can be solved for endogenous variables as a function of de, obtaining for example, the equilibrium change in $d p^{\prime}$ as

$$
\begin{aligned}
& d \mathbf{p}^{\prime}=\boldsymbol{1}-(\mathbf{E} \ldots-\boldsymbol{\pi} .)^{\prime} \boldsymbol{\pi} . .+\boldsymbol{I}\left(\mathbf{q}^{\prime}-\mathbf{q}^{d}\right. \\
& \left.+\boldsymbol{\rho}^{I} \boldsymbol{\pi} . .\right)\left.(\mathbf{E} . .-\pi .)^{\prime} \boldsymbol{\alpha}\right|^{\prime}(\mathbf{E} \\
& \text { - } \pi \text {. ) ' } \boldsymbol{\alpha}^{\prime} \mid \rho^{\prime} \pi \ldots+\left(\mathbf{q}^{\prime}-\mathbf{q}^{d}\right. \\
& \left.+\boldsymbol{\rho}^{\prime} \pi \ldots\right)(\mathbf{E} . .-\pi . .)^{\prime} \pi . \| d \rho
\end{aligned}
$$

where superscript $l$ represents transpose (For extraction of the numéraire good alone, $\boldsymbol{\alpha}=\mathbf{0}_{\lambda}$, and the second expression in brackets can be shown to disappear.) The solution to the system of equations also provides an estimate of the slope $d r / d \rho$, but as Diewert points out, this in the gradient of $r$ with respect to $p$ at the distorted equilibrum point (point A in figure 11, whereas at the reference equilibrium point (point $A()$ ) the slope $d r / d \rho$ must be zero A Harberger type approximatoon to the loss (exact if $r$ wa a quadratic function of $\rho$ ) is

$$
L=-1 / 21-d \mathbf{p}^{\prime \prime} \pi \cdot d \mathbf{p}^{\prime}+d \mathbf{p}^{\prime} E \ldots d \mathbf{p}^{\prime} \mid
$$

which evaluates $d r / d \rho$ as the average of values at point $A$ and point $A C$.

In the empirical example to be considered. there is but one consumer and two commodities (tobaceo and a numeraire good) For such a case. scaling of the uttlity function is arbitrary and may be specified such that $E_{1 "}=1$ (see Diewert), and linear homogenerty of the expenditure function in prices then implies that $p^{c} E_{{ }_{u}}=E_{u}=1$. We consider here only the extraction basket $(1,0)$, 1.e., the loss will be calculated in terms of the imount of the numeraire good that can be extracted. In this simpler case, the values of $d p^{i}$ and $d q$, for example, are

$$
\begin{aligned}
& d p^{\prime}=\frac{-\pi . .}{E . .-\pi . .} d \rho \\
& d q=\frac{\pi . E_{.}}{E . .-\pi . .} d \rho
\end{aligned}
$$

In the approximation to the loss, the wedge between virtual prices and consumer prices is eliminated, so the equations are evaluated at $d \rho$ $=\cdot \rho$. The evaluation of the Allais-Debreu loss using equation (6) for this special case is straightforward.

\section{The Hicks-Boiteux Compensating Variation}

Relaxation of quotas, in the absence of other restrictions permits a Pareto superior reallocation of resources such as depicted at $\mathrm{H}$ in figure 1 No commodities are extracted, so $r=0$ (and $d u$ $\neq$ ()) for this case. The solution to the system of differential equations (4) may now be evalwated. for example for $d p^{t}$, as

$$
\begin{gathered}
\qquad \mathbf{p}^{\prime}=\phi^{1}(\mathbf{E} . .-\boldsymbol{\pi} .){ }^{1}\left\{\mathbf{E}_{u} \boldsymbol{\rho}^{7} \boldsymbol{\pi} . .[I\right. \\
\left.\left.+(\mathbf{E} . .-\boldsymbol{\pi} . .)^{1} \boldsymbol{\pi} . .\right]-\boldsymbol{\phi} \boldsymbol{\pi} . .\right\},
\end{gathered}
$$

For the Robinson Crusoe two-good economy, the solutions for $\mathrm{dp}^{\prime}$ and $\mathrm{dq}$ collapse to

$$
\begin{aligned}
& d p^{\prime}=\frac{-\pi . .+\frac{\rho \pi . .}{p^{\prime}}}{(E . .-\pi . .)+\frac{\rho \pi . .}{p^{\prime}}} d \rho \\
& d q=\frac{-E . . \pi . .}{(E . .-\pi . .)+\frac{\rho \pi . .}{p^{\prime}}} d \rho
\end{aligned}
$$

Again, for loss approximation, these equations are evaluated at $d \rho=-\rho$ and the approximation specified in equation (6) is used.

\section{Application to Deadweight Loss from U.S. Tobacco Quotas}

Tobacco production in the U.S. has been subjected to production limitations since the 1930s, 
first in the form of acreage limits, then in the form of production quotas (the latter beginning in 1965 for flue-cured tobacco and 1971 for burley tobacco.) We evaluate here the alternative deadweight loss measures due to this quota. As we point out above, these loss models are for a closed economy. Since the United States is an open economy, with about $40 \%$ of the U.S. tobacco crop exported, (Alston and Sumner, in fact, argue quite persuasively that tobacco quotas are set close to the level implied by an optimal export tax) this application is more an illustration of the use of the loss measures than an evaluation of U.S. tobacco policy.

We must make additional heroic assumptions, as well. First, we consider the U.S. public to be a single consumer. For the single consumer we can characterize the expenditure function directly, whereas for many consumers the model calls for a utility-allocation constant ("iso-hedonic" in Allais' terms) aggregate expenditure function. We are also able to evaluate $E_{u}=1$ by a scaling argument for the utility function, whereas for the many-consumer economy a more complex and arbitrary welfare function would be required to evaluate any of the Pareto-better utility allocations that would be feasible once the constant-utility-allocation assumption is relaxed. We further assume there are just two commodities, tobacco and a composite numéraire good. This creates a problem in that we have empirical data (prices, quantities, and elasticities) on the raw tobacco market on the one hand and on domestic demand for cigarettes on the other hand. Neither set of numbers conforms conceptually to the requirements of our two-good Robinson Crusoe model, in which tobacco must be a consumer good that is produced using the composite good which is also a consumer good. The assumptions made to resolve these empirical discrepancies are specified below.

We base our empirical estimates on data for the 32 year period (1950-82) examined by Fulginiti and Perrin, during which the average level of tobacco production was 1.8 billion lbs. The average farm price of tobacco, in 1982 dollars, was $\$ 1.80 / \mathrm{lb}$ and the average virtual price was $\$ 1.33 / \mathrm{lb}$, which implies an average price wedge of $\$ 0.47 / \mathrm{lb}$. (Alston and Sumner evaluate the two prices for 1987 as $\$ 1.50$ and 1.25 , which is not inconsistent with the above numbers because both the price and the wedge gradually fell between 1950 and 1990 due to increased foreign competition.) Fulginiti and Perrin estimate the supply elasticity at about 7.0 (compared to Alston and Sumner's 5 to 10 range), which for the average price and quantity implies $\pi . .=16.76$. Although the demand elasticity for raw U.S. tobacco is probably in the vicinity of -1 to -3 , much of this elasticity is due to the availability of both foreign tobacco and other inputs as substitutes for raw U.S. tobacco in the production of cigarettes and other consumables. For this study, we use Alston and Sumner's estimate of domestic demand for cigarettes of -0.3 as the (Marshallian) demand elasticity for our two-good model. The Hicksian price elasticity required would be only slightly smaller than this, due to the small share of incomes spent on cigarettes. Given the average price $(\$ 1.80)$ and quantity ( 1.8 billion lbs) above, this implies $\mathrm{E}$.. $=-0.30$. (Note our assumption here that the entire tobacco crop is consumed domestically.)

Given these parameter estimates, comparisons may be drawn between the two measures of deadweight loss (see table 1.) The Allais-Debreu loss, 0.0758 units of the numéraire good, is graphically represented in figure 1 as the length of line AC-AP in the right panel or as the area $a b c$ in the left panel. The "Allais-Debreu" reference price of tobacco is $p^{A D}=\$ 1.338$, with $q^{A D}=1.939$. The Hicks-Boiteux loss is 0.0776 units of the numéraire good, equal to the length of line $\mathrm{H}^{\prime} \mathrm{H}$ in the right panel or area abde =

Table 1. Comparisons of Allais-Debreu and Hicks-Boiteux Measures of Loss Due to Tobacco Quotas

\begin{tabular}{lcc} 
Variable & Alla1s-Debreu loss & Hicks-Boiteux loss \\
\hline$d p^{\prime}-$ (supply price) & $\frac{E .}{(E .-\pi . .)}(\rho)=00083$ & $\frac{E . .}{(E .-\pi .)+\rho \pi . / p^{c}}(\rho)=0011$ \\
$d p^{\prime}-$ (demand price) & $\frac{\pi .}{(E .-\pi .)}(\rho)=-04617$ & $\frac{-\pi .+\rho \pi / p^{c}}{(E-\pi)+\rho \pi / p^{c}}(\rho)=-0.4589$ \\
$d q-($ tobacco qty) & $\pi d p^{\prime}=0.1385$ & $\pi . d p^{3}=01863$ \\
Loss & $\left.\left[\pi . .\left(d p^{\prime}\right)^{2}-E .\left(d p^{\prime}\right)^{2}\right)\right] / 2=0.03255$ & $\left.\left[\pi . .\left(d p^{\prime}\right)^{2}-E . .\left(d p^{\prime}\right)^{2}\right)\right] / 2=0.03262$ \\
\hline
\end{tabular}


abc + cde in the left pancl. The H1cks-Boiteux reference price and quantity are $p^{\prime \prime S}=1.341$, and $q^{H B}=1.986$. The sizes of these measures of waste relative to the transfer achieved by the quotas $\left(\rho q^{0}=0.846\right.$ units of $\left.\mathrm{x}\right)$, demonstrate that welfare triangles are small (the Allais-Debreu triangle abc is $3.85 \%$ of the total transfer), and that differences among triangles are even smaller (the Hicks-Boiteux triangles are $0.2 \%$ larger than the Allais-Debreu triangle.)

\section{References}

Allass, $M$ "Theories of General Equilibrium and Maxımum Efficiency " Equhlibrium and Disequihrium Theor, G Schwodlauer, ed. D Reidel. Hingham. MA. 1977

Alston. J, and D A Sumner "A New Perspective on the Farm Program for l'S. Tobaceo "Worhing Paper No 88-19, Department of Agricultural Economics. Unı. versity of Calıforna, Davis 1988.

Boiteux. M "Le "Revenu distribuable" et les pertes economiques "Econometrisa 19/Aprll 1951):112-33
I Rebreu. G. "The Coefficient of Resource Utilization." Econometrica 19(July 1951) 273-92.

Inewer, W. E. "The Measurement of Deadweight Loss Revisited." Econometrica 49(September 1981):122544

"The Measurement of Deadweight Loss in an Open Economy." Economica 51(February 1984):23-42.

I Juput, J., "De la Mesure de l'utılité des travaux publıcs" Annales des Ponts et Chaussées 8 Translated and reprinted in K. Arrow and T. Scitovsky, eds.. 1969 , AtA Readings in Welfare Economics, 255-83

I ulgunitı, L., and R Perrn "The Theory and Measurement of Producer Response under Quotas "Rev Econ and Statst 75(February 1993):97-106.

Hicks. J R “Consumers' surplus and index numbers " Rev Fcon Stud 9(June 1942):126-37

Kay, J., and $M$ Keen "Measurnng the inefficiencies of tax systems" J Publ Lion 35(April 1988):265-87.

Iareto, V. "Économe Mathematıque," Encyclopédie des Sclances Mathimatiques, Gauther-Villars, Paris, (1911) 591.641, published in English as "Mathematcal Economes, "Inte' national Eronomics Papers, No. ᄀ. New York, $195558-102$

Tsunckı. A. "The Measurement of Waste in a Public Goods lconomy." I Publ Econ 33(June 1987):73-94 